\title{
A case report on serous cyst fibroadenoma of ovary
}

\section{Saloni Jain*, Mamta Tyagi, Smriti Gupta, Yamini Verma, Swati Shukla, Drishti Chaudhary}

Department of Obstetrics and Gynecology, Subharti Medical College, Meerut, Uttar Pradesh, India

\author{
Received: 28 June 2021 \\ Revised: 02 August 2021 \\ Accepted: 03 August 2021

\section{*Correspondence:} \\ Dr. Saloni Jain, \\ E-mail: intsaloni.012@gmail.com
}

Copyright: (C) the author(s), publisher and licensee Medip Academy. This is an open-access article distributed under the terms of the Creative Commons Attribution Non-Commercial License, which permits unrestricted non-commercial use, distribution, and reproduction in any medium, provided the original work is properly cited.

\begin{abstract}
A 16-year-old unmarried female patient presented to the Subharti hospital with a lump in her abdomen that had been there for one year. For the previous two months, there had been abdominal pain. Constipation, intermittent fever, and vomiting were all present. A mass of around $25 \times 25 \mathrm{~cm}$ (approximately) was found on per-abdominal examination, which was firm in consistency, non-tender, afebrile to touch with smooth borders, and restricted mobility. On the basis of the above mentioned examination and investigation, a diagnosis of ovarian cyst with typhoid immunoglobulin $\mathrm{G}$ (IgG) and immunoglobulin M (IgM) positive, dengue IgG with hepatitis B surface antigen (Hbs Ag) positive was made.
\end{abstract}

Keywords: Fibroadenoma, Ovary, Ovarian cyst

\section{INTRODUCTION}

The most prevalent ovarian neoplasms are surface epithelial-stromal tumours, which affect women in their fourth to sixth decade. Benign serous tumours of the ovary make for about 16 percent of all ovarian epithelial neoplasms, with 30-50 percent of these being bilateral. The fibroblastic stromal component of some serous neoplasms is overly dominant, manifesting as solid, white, nodular foci in otherwise normal cystic neoplasms. These, too, can be classified as benign (adenofibroma and cystadenofibroma), borderline (adenofibrocarcinoma and cystadenofibrocarcinoma), or malignant (adenofibrocarcinoma and cystadenofibrocarcinoma). ${ }^{1,2}$ The benign serous tumours that most commonly originate in the surface or cortex of the ovaries are generally metachronous in origin, with intervals ranging from three to fourteen years. Occasionally, benign serous tumours are accompanied by similar tumours in extraovarian locations. Ovarian cystadenofibroma is a benign tumour that affects women between the ages of 15 and $65 .^{2}$ Although the tumor's routine imaging findings may resemble those of a malignant neoplasm, the presence of the fibrous component often gives it a distinct/characteristic magnetic resonance imaging (MRI) look that can assist distinguish it from malignant ovarian tumours. ${ }^{3-6}$ In this report we present a rare case of serous cyst fibroadenoma of ovary in a 16-year-old female.

\section{CASE REPORT}

A 16-year-old unmarried female patient presented to the Subharti hospital with a lump in her abdomen that had been there for one year. For the previous two months, there had been abdominal pain. Constipation, intermittent fever, and vomiting were all present. The patient's vital signs were steady at the time of the initial checkup. Her blood pressure (BP) was $110 / 70 \mathrm{mmHg}$, and her pulse rate was 96 beats per minute.

A lump of around $25 \times 25 \mathrm{~cm}$ (approximately) was found on per-abdominal examination, which was firm in consistency, non-tender, afebrile to touch with smooth borders, and restricted mobility and lower margin of lump was not appreciated.

On further evaluation with contrast-enhanced computed tomography (CECT) abdomen and pelvis, a large 
abdominopelvic cystic lesion with multiple internal septations possibly arising from right adnexa and minimal bilateral hydroureteronephrosis secondary to ureteral compression by large abdominopelvic cystic lesion was seen.

Additional laboratory tests were performed to confirm the diagnosis. Cancer antigen-125 (CA-125) blood test was carried out. The test determines the level of CA-125 protein in the blood. CA-125 test value came out to be 50.2 $\mathrm{U} / \mathrm{ml}$, beta human chorionic gonadotropin ( $\beta-\mathrm{hCG})$ test showed a value $<1.20 \mathrm{mlU} / \mathrm{ml}$, alfa fetoprotein (AFP) showed a value of $2.07 \mathrm{ng} / \mathrm{ml}$, lactate dehydrogenase (LDH) test came out to be $418 \mathrm{U} / 1$.

The patient tested positive for dengue immunoglobulin $G$ (IgG) and typhoid immunoglobulin $\mathrm{M}(\mathrm{IgM})$ and $\mathrm{IgG}$, for which a medication referral was made and guidance was followed.

On the basis of the above mentioned examination and investigations a diagnosis of ovarian cyst with typhoid IgG and $\operatorname{IgM}$ positive, dengue $\operatorname{IgG}$ with hepatitis B surface antigen (HbsAg) positive was made.

After all recommended pre-operative examination, the patient was scheduled for laparotomy. The right fallopian tube and ovary were revealed to be normal intraoperatively. The uterus appeared to be in normal condition.

A $25 \times 25 \mathrm{~cm}$ left ovarian cyst with a smooth surface and a normal-looking capsule was found. The peritoneal washing was sent to be analysed by cytologists. The omentum appeared normal, with no lymphadenopathy. The cytology of peritoneal washing revealed that there were no malignant cells present. The left salpingo oophorectomy was performed, and the left ovarian cyst and left fallopian tube were removed and histopathologically examined.

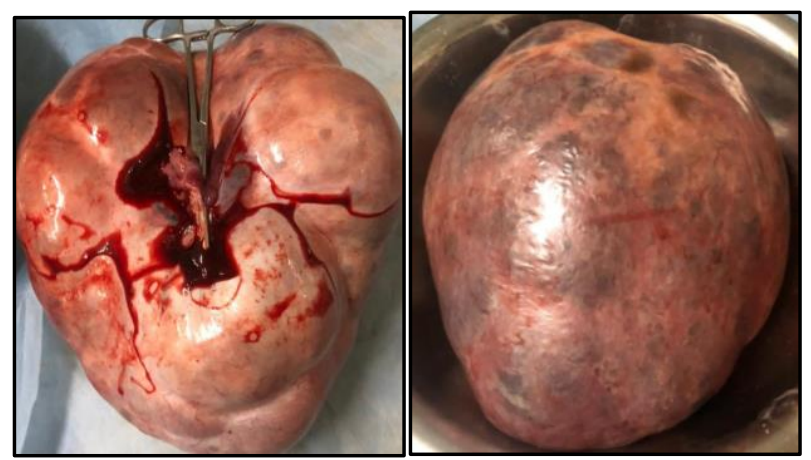

Figure 1: (a) During surgery, and (b) an ovarian cyst removed intact.

\section{DISCUSSION}

Ovarian serous adenofibromas are a rare type of ovarian serous surface epithelial tumour. Abdominal discomfort or a palpable mass in the pelvis or lower abdomen are the most common symptoms of a benign ovarian tumour. Further stages of ovarian tumours can be identified by the appearance of vaginal haemorrhage, ascties, and a mass on vaginal inspection, all of which indicate spread through the bilateral pelvic gutters and cul de sac.

Unless medically treated, a typical serous adenoma is a benign lesion with no future repercussions. Certain benign serous epithelial tumours, such as serous cyst adenofibroma, can have a clinical presentation that resembles carcinoma, and they can be restricted to one ovary or spread to the contralateral ovary. On histology, the present case included several round to oval masses that filled the peritoneal cavity and displayed signs of benign cyst adenofibroma. The sources of such a large number of lumps in a benign cyst adenofibroma are unknown. Adenofibromas of the serous cyst might appear as solid numerous nodules that can spread to extraovarian sites such as the coelomic or peritoneal cavity.

Histologically, the tumours are assumed to arise from the epithelium that normally lines the outside aspect of the ovary, which is known as surface, coelomic, or germinal epithelium. ${ }^{7}$ This epithelium is connected to the mesothelium that covers the peritoneal cavity, forming a modification of it and having many morphologic characteristics with it. ${ }^{8}$

There have been two interesting case reports on serous adenofibroma of ovary, both presenting in different clinical spectrums. The first case was reported by Hughesdon in the proceedings of the royal society of medicine, in which the patient had bilateral ovarian tumours, but because of the pinpoint hemorraghic appearance of both ovaries, as well as blood collection in the pouch of Douglas, a clinical impression of associated endometriosis was suspected eventually on histopathological examination. ${ }^{9}$

On radiological ultrasonography and computed tomography (CT) scans, a second case of ovarian adenofibroma showed symptoms that resembled malignancy. Because the ovarian tumour had complex cystic as well as solid parts, the case was suspected of being malignant, and after excision, the case was diagnosed as cyst adenofibroma. ${ }^{10}$

In evaluating this tumour, a CT scan is likewise of little use. All 16 cases of ovarian cystadenofibromas, appearing as complicated cystic masses with solid components, were misinterpreted as malignant ovarian neoplasms on CT scan or magnetic resonance imaging (MRI) in a research by Cho et al. $^{3}$ In the same way as the previous two clinical case reports, the current case report of a unilateral ovarian mass on clinical examination and radiological findings was found to be highly suspicious of an infectious process or malignancy, but histopathological examination revealed it to be benign serous adenofibroma of ovary. 


\section{CONCLUSION}

As a result, it can be concluded that benign tumours with a good prognosis can occasionally be confused with a grave diagnosis, both clinically and radiologically. It is critical to use frozen section-based histopathological intraoperative diagnosis to aid in the prompt management of such tumours, which will undoubtedly aid in the entire surgical management and prevention of recurrence.

Funding: No funding sources

Conflict of interest: None declared

Ethical approval: Not required

\section{REFERENCES}

1. Compton HL, Finck FM. Serous adenofibroma and cystadenofibroma of the ovary. Obstet Gynecol. 1970;36:636-45.

2. Czernobilsky B, Bornstein R, Lancet $\mathrm{M}$. Cystadenofibroma of the ovary. A clinicopathologic study of 34 cases and comparison with serous cystadenoma. Cancer. 1974;34:1971-81.

3. Cho SM, Byun JY, Rha SE, Jung SE, Park GS, Kim BK, et al. CT and MRI findings of cystadenofibromas of the ovary. Eur Radiol. 2004;14:798-804.

4. Jung DC, Kim SH, Kim SH. MR imaging findings of ovarian

cystadenofibroma cystadenocarcinofibroma: clues for differential diagnosis. Korean J Radiol. 2006;7:199-204.

5. Takeuchi M, Matsuzaki K, Kusaka M, Shimazu H, Yoshida S, Nishitani $\mathrm{H}$, et al. Ovarian cystadenofibromas: Characteristic magnetic resonance findings with pathologic correlation. J Comput Assist Tomogr. 2003;27:871-3.

6. Outwater EK, Siegelman ES, Talerman A, Dunton C. Ovarian fibromas and cystadenofibromas: MRI features of the fibrous component. J Magn Reson Imaging. 1997;7:465-71.

7. Bell DA. Ovarian surface epithelial-stromal tumors. Hum Pathol. 1991;22:750-62.

8. Blaustein A. Peritoneal mesothelium and ovarian surface cells--shared characteristics. Int J Gynecol Pathol. 1984;3:361-75.

9. Hughesdon PE. Adenofibroma of ovary with partial differentiation to endometriosis. Proc R Soc Med. 1949;42:62.

10. Wasnik A, Elsayes K. Ovarian cystadenofibroma: A masquerader of malignancy. Indian J Radiol Imaging. 2010;20:297-9.

Cite this article as: Jain $S$, Tyagi $M$, Gupta $S$, Verma Y, Shukla S, Chaudhary D. A case report on serous cyst fibroadenoma of ovary. Int J Reprod Contracept Obstet Gynecol 2021;10:3604-6. 